\title{
Pas de Tombeaux pour la Reine
}

\author{
Nadine Ltaïf
}

\section{The Queen Has No Tomb}

A diary, a travelog, a record of the unrecorded as the speaker visits ruins in which there is no trace of lost women, only echoes of wars, invasions, "liberations," the names of kings. And a fourth temple, roman or greek, of which only a few columns remain. Excavations have failed to determine to whom this temple was dedicated. Anonymity or erasure? While the names of kings still shine: Ahiram, Melquart... those of the queens don't exist. And those of the goddesses: forgotten. The sea keeps quiet about the secrets of women's bodies, dead or alive, which have no tombs, no burial but the sea, as if woman and the sea were enmeshed forever. The body of woman returns to the sea; the body of man, to the earth. The ultimate dispossession.

\section{Hier, Byblos}

Notre rencontre avec Hyame, archéologue-guide. Une chance incroyable. Elle sait tout par coeur. Mais le plus merveilleux: son innocence. Et son optimisme. Elle n'est pas mariée. S'est-elle consacrée aux temples sans le savoir? Elle a oublié. Trois temples: celui d'Ishtar (rasé), celui de son époux, dont il ne reste plus aucune pierre et le temple des obélisques (dont je n'ai pas compris le sens). Elle a aussi parlé d'un château perse, rasé aussi par les Francs pour ses pierres. Les Musulmans, respectaientils mieux les temples des autres civilisations que les Francs qui, eux, réutilisaient les pierres?

Les fouilles de Byblos n'ont montré qu'un vaste champ de ruines. Ruines à entendre comme écho à la guerre. La guerre depuis l'Antiquité. Surtout millénaire, historique.

A me rendre hystérique.

Et un quatrième temple, romain ou grec, qui n'a gardé que quelques colonnes qui s'élancent dans le ciel face à la mer. Les fouilles n'ont pas su déterminer si le temple fut dédié à quelqu'un en particulier. Avec les 
pierres de tous les temples, les Croisés élevèrent un château-fort par lequel notre visite a débuté. Car on commence par le plus vénéré: la guerre. Récit de guerres, d'invasions ou de libérations du joug musulman, ce qui n'est pas mieux. Ne me reste qu'une immense frustration. Une béance dans l'Histoire. Alors que les noms des rois scintillent encore: Ahiram, Melquart...ceux des reines sont inexistants et ceux des déesses, oubliés.

J'avance et je cherche à tâtons. Comme on pénètre dans la tombe d'un roi. Dans le noir. Je ne trouve évidemment rien. J'essaie de fouiller mais sous la chaleur, entre midi et quatorze heures, je ne fais que tituber. Le soleil brûle ma mémoire. Et il ne reste rien. J'évite de culbuter comme un ivrogne. Une folle, plutôt.

Les Croisés n'ont pas su lever la pierre qui recouvre le tombeau des rois. S'ils avaient pu, auraient-ils utilisé celle des huit puits où sont enterrés, selon le rite phénicien (repliés sur eux-mêmes), les corps momifiés des rois antiques?...

Deux trônes s'élèvent face à la mer. Pour le roi et pour la reine qui méditent en la regardant. La Méditerranée, au mois d'août. Calme comme de l'huile d'olive. La fleur d'acanthe des chapiteaux romains sous les cyprés encense. Il y a une alchimie qui nous englobe dans un mystérieux ensorcellement. A force de regarder la pierre antique, ne reste plus rien des siècles ultérieurs. On oublie le vingtième siècle. Un théâtre minuscule subsiste. L'autre n'existe plus.

Tout ce qui n'existe plus continue pourtant à hanter les lieux. Le temple dédié à la déesse. Les quelques signes gravés sur les pierres, codes des sectes religieuses: croix des esclaves juifs, poisson qui symbolise les premiers Chrétiens...symbole de malédiction en phénicien ou en araméen...

Et la mer qui se tait sur les secrets des corps féminins morts ou vivants, qui n'ont pas eu de sépulture, pas d'enterrement...que la mer. Comme si la femme et la mer étaient soudées à jamais. Le corps de la femme retourne à la mer, celui de l'homme retourne à la terre. Quelle ultime dépossession.

Ils ne se rejoindront jamais sur cette terre qui ne connut que les guerres.

Délicieuse terre. 